\title{
Studies on the Soft Scale Insect Kilifia acuminata (Signoret) (Hemiptera: Coccidae) is a Main Insect Pest Attacking Mango Trees. Awadalla, S. S. ${ }^{1}$; E. S. El-Zahi' ${ }^{2}$ and M. A. Abdel-Fattah ${ }^{2}$ \\ ${ }^{1}$ Economic Entomology Department, Faculty Agriculture, Mansoura University. \\ ${ }^{2}$ Plant Protection Research Institute, Agriculture Research Center.
}

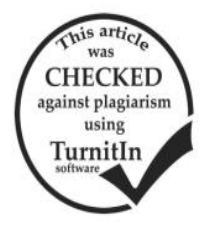

\section{ABSTRACT}

The soft scale insect kilifia acuminata (Signoret) (Hemiptera: Coccidae) is one of the main insect pests infesting mango trees and caused the damage for leaves and fruits. The population density of the soft scale insect $k$. acuminata during the first year of study 2014/15 recorded 6 peaks and the highest peak was 1539 indiv.on $27^{\text {th }}$ of March, 2015. While recorded 5 peaks during the second year $2015 / 16$ and the highest peak was on $17^{\text {th }}$ of June 2016 and represented by 1178 indiv. The highest average number and percentage in the first year was recorded during autumn season and represented by 1023.1 indiv. /100 leave $(30.2 \%)$, while the highest average number and percentage was recorded during spring and represented by 994.8 indiv./100 leaves $(29 \%)$ in the second year. The highest average number of the soft scale insect $K$. acuminata were recorded in the south direction during the two successive years $2014 / 15$ and $2015 / 16$ and represented by $225.9 \pm 19.6$ and $241.4 \pm 18.3$ indiv. / 100 leaves, respectively. On the other hand, the lowest average number were recorded in the North direction and represented by $105.4 \pm 16.1$ and $74.8 \pm 6.2$ indiv. $/ 100$ leaves, respectively. Statistical analysis showed that, a highly significant differences between the different directions, during the two successive year of study.

\section{INTRODUCTION}

Mango (Mangifera indica L.) is an important fruit crop of the tropical and subtropical regions. Also, it is one of the most common and popular fruit sand considered the king of fruits having delicious taste, captivating flavor with multifarious color, and excellent source of nutritive values (Abd-Rabou et al..2012). In Egypt, Mango occupied about 110336 Feddans with total production of about 596758 tons according to the last statistics of the Ministry of Agriculture (2010).

The soft scale insect kilifia acuminata (Signoret) (Hemiptera: Coccidae) is one the common insect pests attacking different fruit trees and ornamental plants and the damage of this insects caused mainly to the leaves of the host plants (Elwan 1990, Hassan 1993, Atalla et al. 2007 and Attia and Radwan 2013).

A few studies carried out in Egypt on the effect of different direction on the population density of these insect pest as well as different season during the year (Elwan, 1990; Kwaiz, 1999; Elwan, 2007 and AbdelRahman et al. 2012).

Therefore, the present experiments aimed to study the population density during the two successive years, effect of different season and different direction on the average number of these insect pest on mango trees to serve as a basis for the use of this informations in in integrated pest management programs.

\section{MATERIALS AND METHODS}

The present studies were carried out in mango orchard in Desouk district, Kafr EL-Sheikh Governorate Egypt to evaluate the population density of the soft scale insects infesting mango trees Mangifera indica $L$. during the two successive years 2014/15 and 2015/16.

Four mango trees of the same size, age, shape and vegetative growths were selected a replication. Leaf samples were taken biweekly during the two successive years from July 2014 till June 2015 in the first year and from July 2015 till June 2016 in the second year. Each sample consisted of 100 leaves were randomly collected from the four mango trees (25 leaves from each tree when 5 leaves were collected from the four direction plus five from the middle of the tree). The collected leaves were transferred to the laboratory for identification and counting the soft scale insect to evaluate the population density on mango trees as well as evaluate the effect of different season and directions on the average number of these insect pests.

\section{RESULTS AND DISSCUSION}

\section{Population density:}

The population density of the soft scale insect $k$. acuminata during the first year of study recorded six peaks on mango trees during the first year 2014/15 at Desouk district. The highest peak recorded on $27^{\text {th }}$ of March 2015 and represented by 1539 indiv, while the lowest one recorded on $5^{\text {th }}$ June 2015 and represented by 627 indiv (Fig. 1). In the second year (2015/16), it recorded five peaks at Desouk district. The highest peak recorded on $17^{\text {th }}$ of June 2016 and represented by 1178 indiv. The lowest one recorded on $22^{\text {th }}$ April 2016 and represented by 922 indiv.

The obtained results are in consistent with those of Salem (1994), Atalla et al. (2007) and Attia and Ramadan (2013). They mentioned that, the insect pest had different peaks of abundance on mango trees. The highest peaks were recorded in April and November.

\section{Effect of different seasons:}

The seasonality average numbers and percentages of the coccid scale $K$. acuminata on mango trees during the two successive years 2014/15 and 2015/16 at Desouk district Kafr El-Sheikh Governorate are presented in Table (1). The highest average number and percentage in the first year was recorded during autumn season and represented by 1023.1 indiv. /100 leave $(30.2 \%)$ and the lowest one was estimated during summer season and represented by 619.8 indiv. /100 leave $(18.3 \%)$ Table (1). Meanwhile in the second year2015/16 that the highest average number and percentage was recorded during spring and represented by 994.8 indiv./100 leaves $(29 \%)$ while the lowest one was recorded during summer season and represented by 771.5 indiv. $/ 100$ leave $(22.6 \%)$ Table (1). 


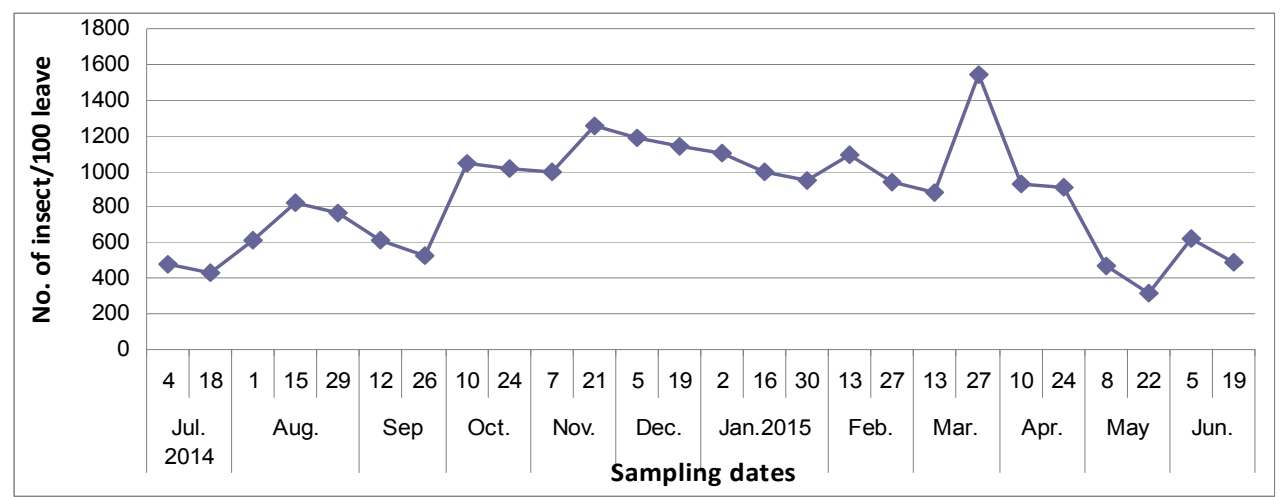

Fig. 1. Population density of $k$. acuminata during the first year 2014/15 at Desouk district, Kafr El-Sheikh Governorate.

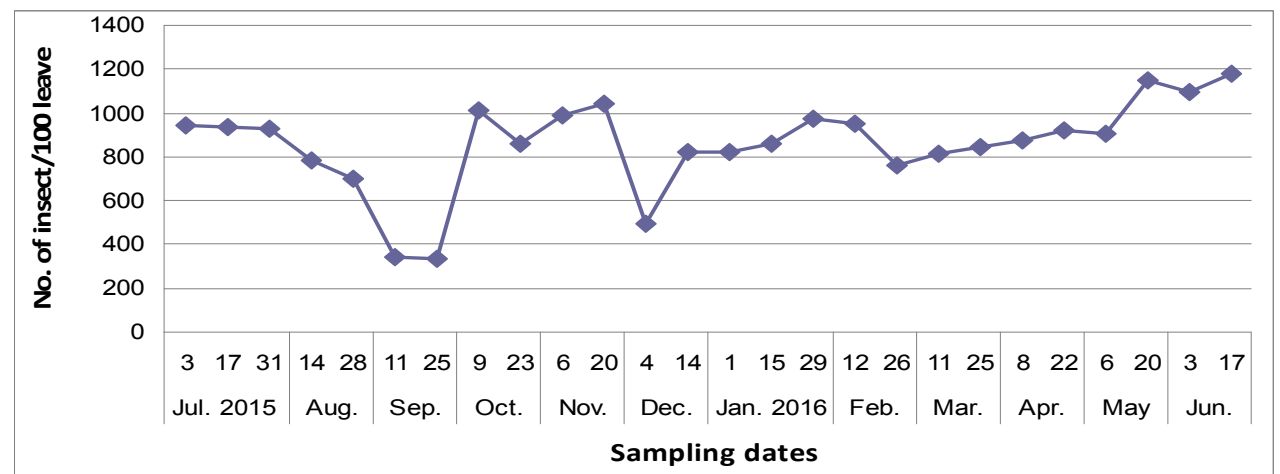

Fig. 2. Population density of $k$. acuminata during the Second year 2015/16 at Desouk district, Kafr El-Sheikh Governorate.

Table 1. Seasonality average numbers and percentage of the soft scale insect $K$. acuminata on mango trees during the two successive years $2014 / 15$ and 2015/16 at Desouk district Kafr El-Sheikh Governorate.

\begin{tabular}{lcccccc}
\hline \multirow{2}{*}{ Seasons } & \multicolumn{2}{c}{ Frist year } & \multicolumn{3}{c}{ Second year } \\
& NO. & \% & NO. & \% \\
\hline Summer & 619.8 & d & 18.3 & 771.5 & c & 22.6 \\
Autumn & 1023.1 & a & 30.2 & 792.8 & c & 23.1 \\
Winter & 990.5 & b & 29.2 & 865.3 & b & 25.3 \\
Spring & 753.8 & c & 22.3 & 994.8 & a & 29 \\
Total & 3387.2 & 100 & 3424.4 & 100 \\
\hline
\end{tabular}

Averages followed by the same letter in a column are not significantly different at 0.05 level of probability (Duncan's Multiple Range Test).

The obtained results are in consistent with those of Kwaiz (1999), who found that, the highest densities of the insect pest were in late autumn and early summer and Elwan (2007) who found that, the highest generation of the insect on mango trees recorded in autumn.

\section{Effect of different directions}

The monthly average numbers of the coccid insect, $K$. acuminata according on the different directions of mango trees during the first year 2014/15 and 2015/16 at Desouk district Kafr El-Sheikh Governorate are presented in Tables (2 and 3). The highest average number for the different directions were recorded in November 2014 for north and middle directions, March 2015 for east, December 2014 for west and March 2015 for south direction . on the other hand, the lowest average number for the different direction were recorded in May 2015 for north, east, middle and west directions, while for south direction was recorded in July 2014 (Table 2).
Table 2. Monthly average numbers of the soft scale insect $K$. acuminata according to the different directions of mango trees during the first year 2014/15 at Desouk district Kafr El-Sheikh Governorate.

\begin{tabular}{lccccc}
\hline \multirow{2}{*}{ Months } & \multicolumn{5}{c}{ Different directions } \\
& North & East & Middle & West & South \\
\hline July2014 & 48 & 108.5 & 70 & 93.5 & 134 \\
August & 55.6 & 196 & 103.3 & 176 & 200.3 \\
September & 45 & 145 & 91 & 136.5 & 156.5 \\
October & 140 & 230 & 203 & 215 & 238.5 \\
November & 168 & 253.5 & 215.5 & 227.5 & 262 \\
December & 160 & 280.5 & 183.5 & 252 & 286.5 \\
January2015 & 138.6 & 241.3 & 152 & 217 & 266.3 \\
February & 159 & 320.5 & 175.5 & 200 & 241.5 \\
March & 166.5 & 345.5 & 189.5 & 151.5 & 358.5 \\
April & 109 & 202.5 & 159 & 174 & 264.5 \\
May & 26 & 101.5 & 43.5 & 69 & 150.5 \\
June & 50 & 147 & 100 & 110.6 & 152 \\
\hline Mean+SE & $105.4 \pm$ & $214.3 \pm$ & $140.4 \pm$ & $168.5 \pm$ & $225.9 \pm$ \\
& $16.1 \mathrm{c}$ & $22.8 \mathrm{a}$ & $16.3 \mathrm{~b}$ & $16.1 \mathrm{~b}$ & $19.6 \mathrm{a}$ \\
\hline
\end{tabular}

Mean followed by the same letters are not significantly different at 0.05 level of probability (Duncan's Multiple Range Test).

During the second year (Table 3), the highest average numbers for the different directions were recorded in November 2015 for north and south directions, and June 2016 for east, middle, and west directions. On the other hand, the lowest average number for the different direction were recorded in September 2015 for all directions. Regarding to different directions, it can be observed that the highest average numbers were recorded in the south direction and represented by $241.4+18.3$ indiv. /100 leaves followed by the East direction and represented by 202.2+14.4 indiv. /100 leaves, and the lowest average 
number was recorded in the North direction and represented by $74.8+6.2$ indiv. $/ 100$ leaves. Statistical analysis revealed that, in the different directions during the second year 2015/16.

Table 3. Monthly average numbers of the soft scale insect $K$. acuminata according to the different directions of mango trees during the first year 2015/16 at Desouk district Kafr El-Sheikh Governorate.

\begin{tabular}{lccccc}
\hline \multirow{2}{*}{ Months } & \multicolumn{5}{c}{ Different direction } \\
& North & East & Middle & West & South \\
\hline July2015 & 92 & 230 & 169 & 203.6 & 240.6 \\
August & 50.5 & 204 & 93.5 & 182 & 210.5 \\
September & 34 & 77 & 59.5 & 71 & 97.5 \\
October & 93 & 226 & 161.5 & 191 & 238 \\
November & 103 & 220 & 156.5 & 189 & 345 \\
December & 70 & 155.5 & 128.5 & 139 & 166 \\
January2016 & 95.6 & 216.3 & 130 & 162 & 261.3 \\
February & 77 & 177.5 & 153 & 168.5 & 282 \\
March & 67 & 186.5 & 158.5 & 184.5 & 233.5 \\
April & 48.5 & 225 & 163 & 204 & 257.5 \\
May & 81.5 & 232.5 & 218.5 & 222.5 & 269 \\
June & 86.5 & 277 & 223 & 255.5 & 296 \\
\hline \multirow{2}{*}{ Mean+SE } & $74.8 \pm$ & $202.2 \pm$ & $151.2 \pm$ & $181.0 \pm$ & $241.4 \pm$ \\
& $6.2 \mathrm{e}$ & $14.4 \mathrm{~b}$ & $13.2 \mathrm{~d}$ & $6.2 \mathrm{c}$ & $18.3 \mathrm{a}$ \\
\hline
\end{tabular}

Mean followed by the same letters are not significantly different at 0.05 level of probability (Duncan's Multiple Range Test).

As a concluation, data represented in Tables (2 and 3) revealed that the highest average number the soft scale insect $K$. acuminata were recorded in the south direction during the two successive years 2014/15 and $2015 / 16$ and represented by $225.9 \pm 19.6$ indiv. /100 leaves and $241.4 \pm 18.3$ indiv. /100 leaves, respectively. On the other hand, the lowest average number the soft scale insect $K$. acuminata were recorded in the North direction and represented by $105.4 \pm 16.1$ indiv. /100 leaves and $74.8 \pm 6.2$ scales /100 leaves, respectively. There were highly significant differences between the different directions in the number of scales during the two successive year of study.

The obtained results agreement with those of (Elwan, 1990) who recorded that the lower and middle parts of the trees were preferable to the insect as compared to the upper parts.

\section{REFERENCES}

Abd-Rabou Sh.; H. Badary and N. Ahmed (2012). Control measures of two soft scale insects (Hemiptera: Coccidae) infesting guava and mango trees in Egypt. J. Basic and Applied Zoology, 65:55-61.

AbdEl-Rahman, A. M. A.; S. F. M. Moussa; Y. Y. Mosleh and M. R. A. Mohamed (2012). The efficiency of certain chemical and non-chemical insecticides against the mango soft scale insect, Kilifia acuminata (Signoret) on mango trees in Ismailia governorate. Egyptian Acad. J. of Biology. Sci. Entomology. 5(1):183-191.

Atalla, Fatma A.; Fayza, A. Kwaiz and A. R. Attla (2007): Seasonal abundance of the mango soft scale insect, Kilifia acuminata (Signoret) (Hemiptera: Coccidae) and its parasitoids in Qalubyia Governorate, Egypt. Bull. Soc. Ent. Egypt, 84: 103-11

Attia A. R. and S. G. Radwan, (2013).On the scale insects infesting mango trees and their parasitoids at Qaluobyia Governorate, Egypt. Egyption. J. Biol. Pest control 23 (1):131-135.

Elwan, E.A. (1990). Ecological and biological studies on certain insects pests of Coccoidea (Homoptera) infesting mango trees. Ph.D. Thesis, Fac. of Agric., Al-Azhar Univ., Egypt 175 pp.

Elwan, E.A. (2007). Population fluctuation of Acuminata scale, Kilifia acuminata (Sign.) (Homoptera: Diaspididae) on mango trees in Egypt Arab J. Plant Prot., 52, No. 1: 32-42.

Hassan, N.A. (1993). Survey and Toxicological studies on citrus Diaspine scale insects and their parasites in Egypt. Ph.D. Thesis, Fac. of Agric., Ain Shams Univ., 204 pp.

Kwaiz, A.M.F. (1999). Ecological and toxicological studies on the mango soft scale, Kilifia acuminata (Signoret) with special reference to insecticide residues in mango fruits. Ph.D. Thesis, Cario, Univ. Egypt, 171 pp.

Ministry of Agriculture and Reclaiming land (2010) Agriculture Economic Report (In Arabic).

Salem, H.A. (1994). Factors contributing to the distribution and level of attack of scale insects which infections some different varieties of mango fruit trees. M.Sc Thesis, Fac. Agric., Zagazig Univ., Egypt, 194 pp.

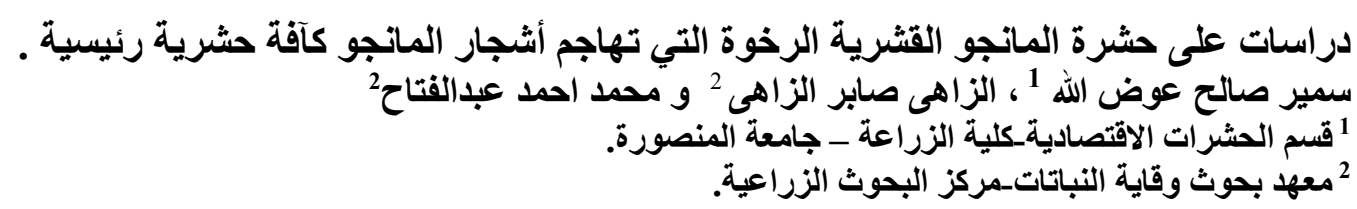

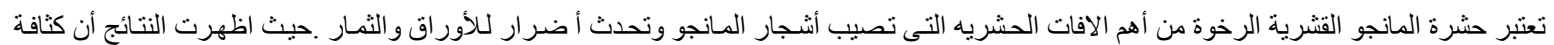

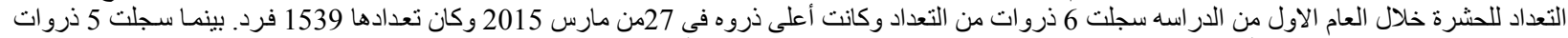

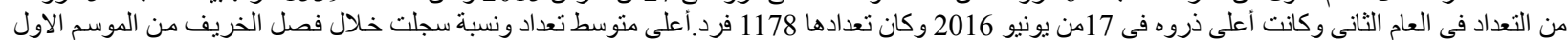

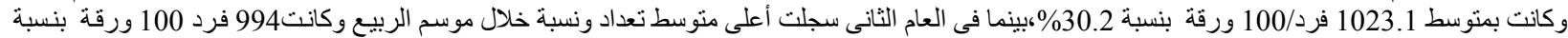

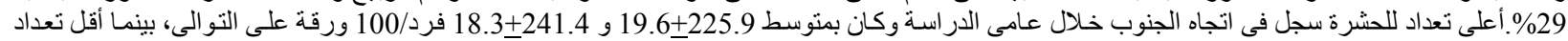

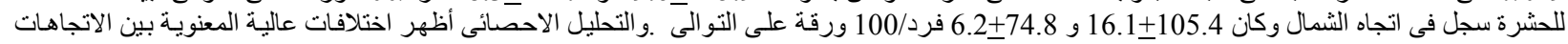

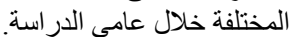

